\title{
Role of MRI in the Diagnosis of Hip Joint Pain
}

\section{Rashmi U Turamari ${ }^{1}$, Prashant B Channaveerappanavar ${ }^{2}$, Arjun Prakash ${ }^{3}$, Naveen Jayaram ${ }^{4}$, Chandrashekar H M $^{5}$, Apoorva Muralidhar ${ }^{6}$}

${ }^{1}$ Senior Resident, Department of Radiology, ${ }^{2}$ senior Resident, Department of Medicine, ${ }^{3}$ Assistant Professor, Department of Radiology, ${ }^{4}$ Assistant Professor, Department of Radiology, ${ }^{5}$ Assistant Professor, Department of Radiology, ${ }^{6}$ Senior Resident, Department of Radiology, Bangalore Medical College and Research Institute, Bengaluru, India

Corresponding author: Prashant B Channaveerappanavar, Senior Resident, Department of Medicine, Victoria Hospital, BMCRI, Bangalore, India

DOI: http://dx.doi.org/10.21276/ijcmsr.2019.4.4.8

How to cite this article: Rashmi U Turamari, Prashant B Channaveerappanavar, Arjun Prakash, Naveen Jayaram, Chandrashekar H M, Apoorva Muralidhar. Role of MRI in the diagnosis of hip joint pain. International Journal of Contemporary Medicine Surgery and Radiology. 2019;4(4):D35-D38.

\section{A B S T R A C T}

Introduction: Hip pain is a common diagnostic challenge for the physician. Study aimed to access the usefullness of Magnetic resonance imaging (MRI) in the diagnosis of various hip pathologies.

Material and methods: This was a prospective study of 80 patients with the complaints of hip joint pain. All patients underwent the following MRI sequences- Axial T1WI, T2WI, Coronal T1WI, T2WI, STIR \& PDFS, Sagittal PDFS and T1WI postcontrast axial, coronal and sagittal sequences. Data was collected and tabulated. Statistical analysis was done with the calculations of frequencies and percentages.

Results: Out of 80 patients 68(85\%) patients revealed abnormalities in the MRI scan. Avascular necrosis is seen in $28(35 \%)$, fractures in $8(10 \%)$, osteoarthritis in $8(10 \%)$, Synovial effusion in $6(7.5 \%)$, bone infarcts in $4(5 \%)$ bursitis in $4(5 \%)$, synovitis, bone marrow oedema, infective arthritis, metastatic lesions, sacroillitis in two patients each and intramuscular abscess and femoro acetabular impingement are seen in one patient each.

Conclusion: MRI is the modality of choice for the diagnosis of hip joint pain as it is safe, non-invasive and depicts accurate anatomical details. MRI is an excellent modality for the diagnosis of many hip conditions which shows nonremarkable subtle findings in radiographs and CT.

Keywords: Avascular Necrosis, AVN Hip, Bone Infarcts, Hip Pain, MRI Hip, Osteoarthritis MRI, Stress Fractures, Synovitis

\section{INTRODUCTION}

The hip joint is a synovial joint that has major weight bearing property and wide range of mobility. Painful hip is a common symptom of all age groups. Etiological causes can include intraarticular, juxta articular pathologies and referred pain from sacroiliac joints and spine.

Trauma, infection, arthritis, avascular necrosis (AVN) and tumours are very difficult to diagnose on radiographs in the early stages. In modern imaging technology, Magnetic resonance imaging (MRI) has a great value in the evaluation of all hip pathologies. Extensive studies have been done on the role of MRI in AVN and it is proved as essential modality in the diagnosis of early stages of AVN, where radiograph is unequivocal. ${ }^{1,2}$ MRI gives valuable information about occult bony injuries and cartilage injuries as stress fractures, occult fractures, bone marrow disorders, infections \& musculoskeletal neoplasms. ${ }^{3}$ Contrast study with intravenous and intra- articular gadolinium is used to diagnose synovial, labral and articular cartilage pathologies and subtle pathologies of femoral head and adjacent soft tissue. ${ }^{4}$ Femoro-acetabular impingement (FAI) is another condition where MRI is useful to detect early changes in tissues before labral tear and cartilage delamination. ${ }^{5}$ Study aimed to access the usefullness of Magnetic resonance imaging (MRI) in the diagnosis of various hip pathologies.

\section{MATERIAL AND METHODS}

This was a prospective study of 80 patients presenting with hip joint pain and referred to the Department of Radiodiagnosis, Victoria hospital, BMCRI, Bangalore from July 2018 to June 2019. Ethical clearance for the study was taken from Institutional Ethics Committee, Bangalore Medical College \& Research Institute.

Patients with pacemakers, metallic implants, cochlear implants and with other MRI contraindications are excluded from the study. Informed consent was taken from all the patients before imaging. Relevant clinical history, examination findings and laboratory investigations were noted.

\section{Technique of examination}

MR imaging of all patients was done using dedicated body coil of Seimens Magnetom Avanto,B15 machine, 1.5 Tesla. Bilateral hips are examined simultaneously in supine position. T1weighted, T2 weighted, proton density fat saturation (PDFS) and short tau inversion recovery (STIR) coronal sequences were taken with $3-5 \mathrm{~mm}$ thickness. T1W, T2W, 
PDFS axial and sagittal sequences were taken with $5-8 \mathrm{~mm}$ thickness. Field of view was 350 to 400 in adult and 160 to 180 in children. Intravenous gadolinium contrast (Teslaview $10 \mathrm{ml}$ ) was given and axial, sagittal and coronal T1weighted fat saturated images were taken.

\section{STATISTICAL ANALYSIS}

Descriptive statistical data was presented in the form of percentages and frequencies for nominal data, while mean, median, minimum, maximum and standard deviation for continuous, discrete variables. The results were presented in the form of tables and charts.

\begin{tabular}{|l|c|c|}
\hline Risk factors & Number of patients & Percentage\% \\
\hline Idiopathic & 15 & 53.5 \\
\hline Alcohol & 5 & 17.8 \\
\hline Trauma & 3 & 10.7 \\
\hline Steroids & 2 & 7.1 \\
\hline Pancreatitis & 2 & 7.1 \\
\hline Sickle cell anaemia & 1 & 3.5 \\
\hline \multicolumn{2}{|c|}{ Table-1: Risk Factors for AVN } \\
\hline
\end{tabular}

\begin{tabular}{|l|c|c|}
\hline MRI findings & $\begin{array}{c}\text { Number } \\
\text { of femoral } \\
\text { heads }\end{array}$ & Percentages\% \\
\hline $\begin{array}{l}\text { Focal subchondral signal abnor- } \\
\text { mality }\end{array}$ & 38 & 100 \\
\hline Hip joint effusion & 22 & 57.8 \\
\hline Bone marrow oedema & 18 & 47.3 \\
\hline Collapse of Head & 15 & 39.4 \\
\hline Decreased joint space & 15 & 39.4 \\
\hline Double line sign & 13 & 34.2 \\
\hline Osteophytes & 10 & 26.3 \\
\hline Thinning of articular Cartilage & 8 & 21 \\
\hline Subchondral cysts & 8 & 21 \\
\hline \multicolumn{2}{|c|}{ Table-2: MRI Findings in AVN } \\
\hline
\end{tabular}

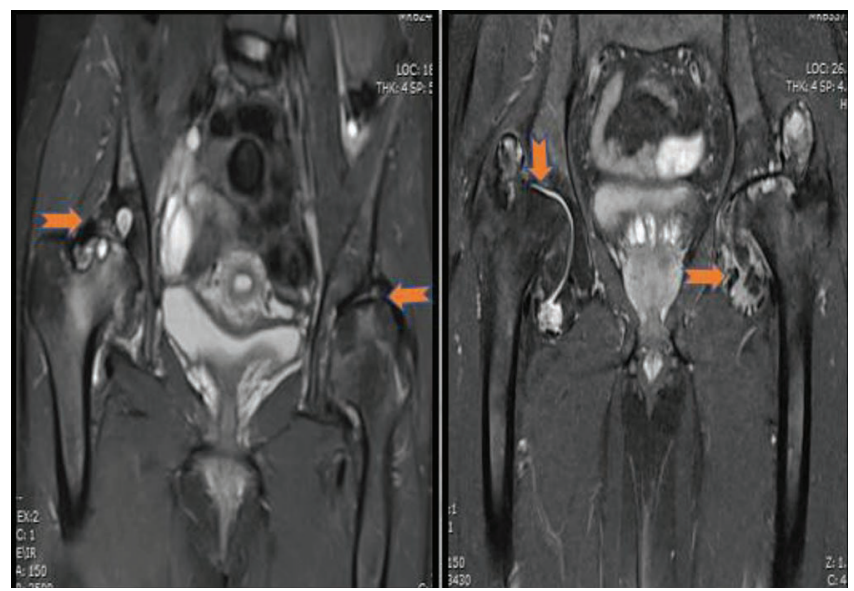

Figure-1: A-T2 FAT SAT coronal image showing features of avascular necrosis of bilateral femoral heads - Ficat \& Arlet Stage-IV on right side and Ficat \& Arlet Stage-II on left side: B-Proton density fat sat coronal image showing features of avascular necrosis of bilateral femoral head - Ficat \& Arlet Stage-IV

\section{RESULTS}

We studies MRI scans of 80 patients with history of painful hip joint. The age of the patients was ranging from 5 years to 74 years. The maximum number of patients $22(27.5 \%)$ belongs to the age group of 41-50 years. Out of 80 patients with hip pain complaints, MRI of 12 cases was normal. Rest

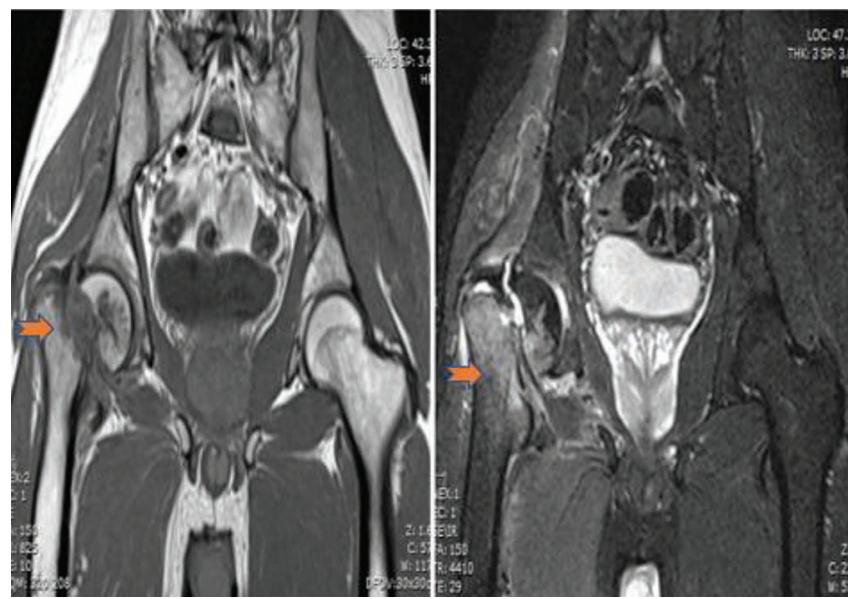

Figure-2: T1W and STRI images of old non united fracture of right femur neck, fracture line being hypointense on T1WI and hyperintense on STRI image with adjacent marrow oedema and minimal joint effusion.
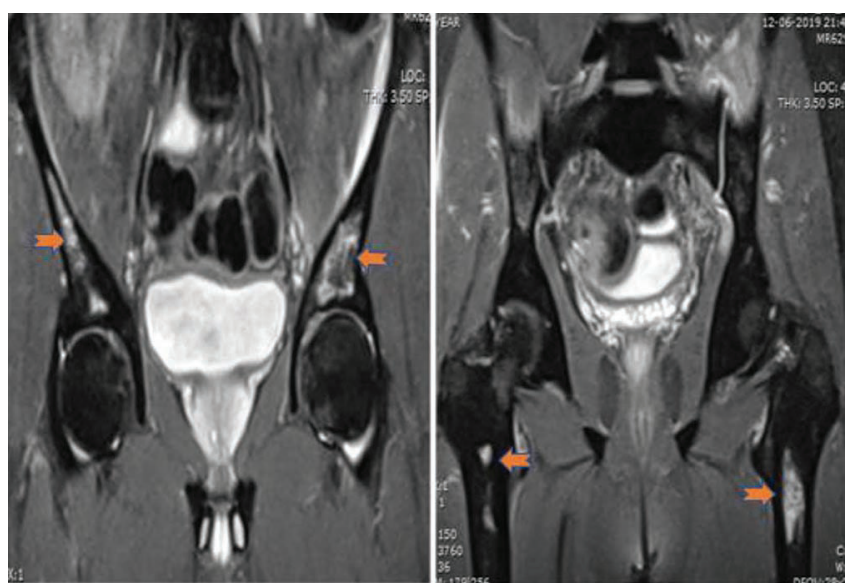

Figure-3: Coronal STIR images of a known case of sickle cell anaemia showing multiple ill defined hyperintense lesions involving bilateral iliac bones and proximal femurs suggestive of bone infarcts.

Spectrum of MRI findings Number of patients

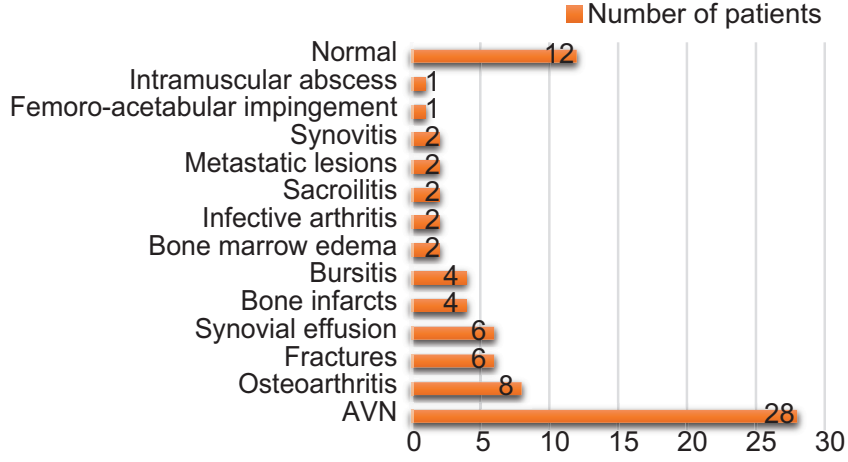

Chart-1: Spectrum of MRI findings 


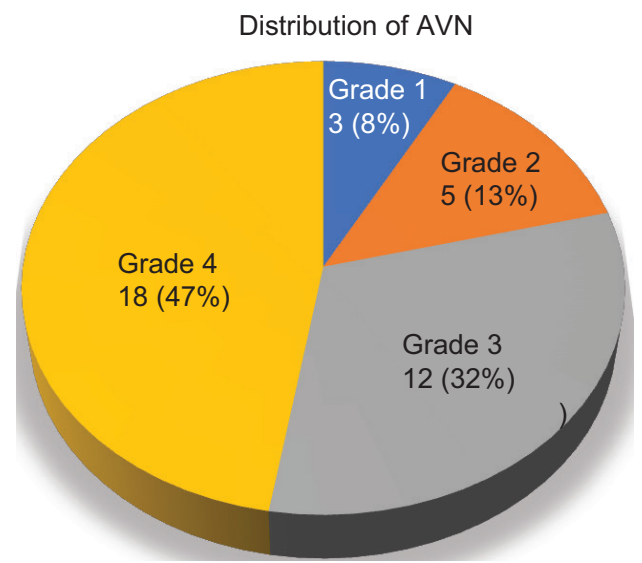

Chart-2: Distribution of AVN Cases According to Ficat \& Arlet classification

68 patients showed various abnormalities on MRI scan as listed in chart 1 . The study shows AVN as the most common pathology of hip joint accounts for $35 \%$ of all cases. On evaluation of risk factors, idiopathic is the most common and observed in $53.5 \%$ of cases. Rest of the causes and their frequencies are presented in Table 1 . Unilateral AVN is seen in 18 patients (64.2\%) and bilateral AVN is seen in 10 patients (35.8\%). Focal subchondral signal intensity changes are the most common finding of AVN, and is seen in all the 28 cases (100\%). Rest of the findings and frequencies are tabulated in table 2. Our study shows Stage 4 of Mitchells classification as the most common class of AVN, seen in $47 \%$ of the lesions, followed by stage 3 in 40\% (15), stage 2 in $8 \%$ (3), and stage 1 in 5\% (2) of cases. Our study shows Grade IV- Ficat \&Arlet classification as the most common class of AVN seen in $47 \%$ of cases. Distribution of grades of AVN is presented in chart 2 .

\section{DISCUSSION}

Common findings of MRI of painful hip joint are discussed below.

\section{Avascular Necrosis}

MRI is an excellent modality for the diagnosis of AVN. MRI helps in the early diagnosis and accurate staging of AVN with clear depiction of size of the lesion.

This study shows avascular necrosis as the most common pathology of hip pain (35.5\%). Idiopathic AVN accounts for $53.5 \%$ cases, which turns out as most common cause, followed by alcohol in $17.8 \%$ and steroids in $7.1 \%$ of cases. In the study done by Jacobs B et $\mathrm{al}^{6}$, alcohol was the commonest risk factor, seen in $39 \%$ of cases. Kamal D et $\mathrm{al}^{7}$ concluded smoking is the commonest risk factor in her study which contributed to $36.9 \%$ of cases.

In our study, unilateral AVN was seen in 18 patients (64.2\%) and bilateral AVN in 10 patients (35.8\%). In a study by Drar HA et $\mathrm{al}^{8}$, shows unilateral AVN in $68 \%$ and bilateral AVN in $32 \%$ of patient.

In our study, $47 \%$ of the lesions were in stage $\mathrm{D}$, followed by stage $\mathrm{C}$ seen in $40 \%$ lesions. A study by Mitchell DG et $\mathrm{al}^{9}$, concluded stage $\mathrm{A}$ as the most common (43\%) lesion; as their study was on early AVN. In our study, Ficat\&Arlet classification grade IV is the commonest grade of AVN seen in $47 \%$ of the lesions. Study by Kamal D et $\mathrm{al}^{7}$ shows $51.09 \%$ of patients with grade IV and $34.78 \%$ of patients with grade III AVN.

Drar HA et $\mathrm{al}^{8}$, in his study concluded that $100 \%$ patients of AVN had focal subchondral signal abnormality in MRI, as comparable to our study where all the patients had focal subchondral signal abnormality.

\section{Osteoarthritis}

MRI findings of osteoarthritis include non specific joint effusion, diffuse bone marrow oedema, subchondral insufficiency fractures at the weight bearing area, subchondral cyst like lesions, femoral head flattening, epiphyseal low signal intensity lines. We had eight patients of osteoarthritis in our study presenting with hip pain. Bone marrow oedema and joint effusion were present in all the patients. Subchondral cysts, fractures and bone flattening were present in five cases.

\section{Fractures}

Deutsch $\mathrm{AL}$ et $\mathrm{al}^{10}$ have reported that $\mathrm{T} 1$-weighted coronal images of MRI can accurately depict occult hip fractures. Stress fractures and non-displaced subtle fractures are very difficult to appreciate on radiographs but can be easily recognized on MRI images on STIR or fat suppressed T2 weighted sequences due to marrow oedema. ${ }^{10,11}$

In our study, 8 patients had fracture of hip bones, 6 patients had femur neck fractures, one patient had acetabulum fracture and one patient had stress fracture. MRI finding in those cases showed linear hypo intensity (100\%) on T1W images and bone marrow oedema on STIR images (100\%).

\section{Bone Infarct}

Numerous causes which interrupts the blood supply to bone marrow leads to bone infarcts. Our study shows four patients of bone infarcts presenting with hip pain. One of the patients was a case of sickle cell anaemia, had multiple pelvic bone infarcts. Multiple ill-defined lesions of varying sizes were noted involving pelvic bones, which are hypointense with a sclerotic rim on T1WI, hyperintense on T2WI with a surrounding hypointense rim (double line sign). On contrast study peripheral rim enhancement was noted.

\section{Bursitis}

Trochanteric bursitis or greater trochanter pain syndrome is characterized by lateral hip pain due to inflammation of bursa and adjacent structures. ${ }^{12}$ Our study had four patients with trochanter bursitis. MRI shows enlarged bursa with T2, STIR hyperintensities of adjacent tendons.

\section{Sacroiliitis}

MR imaging findings of sacroiliitis includes bone marrow oedema, articular cartilage changes, narrowing of joint space, cortical erosions. We had two patients of sacroiliitis, with bilateral involvement. One of the patients had ankylosis with secondary hip osteoarthritis.

\section{Infective arthritis}

In his study, Michael Karchevsky $\mathrm{M}$ et $\mathrm{al}^{13}$, has described MRI findings of infective arthritis, which includes synovial thickening and enhancement, joint effusions, peri synovial bone oedema, fluid out pouching and enhancement of adjacent soft tissue. In our study, two cases of infective 
arthritis were detected. MRI findings of these cases includes bone marrow oedema, joint effusion, synovial thickening and contrast enhancement of synovium (50\%).

\section{Synovitis}

MR imaging of synovitis shows synovial thickening and enhancement with joint effusion. Absence of significant bone marrow oedema and absence of adjacent soft tissue enhancement differentiates it from infective arthritis. ${ }^{14}$ Our study had two patients of synovitis having bilateral hip joint involvement with effusion, synovial thickening and enhancement.

\section{Metastatic lesion}

As MRI can detect early bone marrow abnormalities, it is more sensitive than nuclear bone imaging in the detection of bone metastasis. ${ }^{15} \mathrm{We}$ had two patients with metastatic lesions presenting with hip pain. Lesions are T1 hypointense, T2, STIR hyperintense and shows enhancement on contrast study.

\section{Intramuscular Abscess}

We had one patient of intramuscular abscess with hip joint pain. The patient had well defined collection in the left gluteus medius muscle with necrotic centre and thick enhancing wall.

\section{Femoro-Acetabular Impingement}

Pincer and cam are the two types of femoro-acetabular impingements. In Pincer impingement femoral head will be overcovered by acetabulum.

In Cam impingement femoral head is in aspherical shape due to bony protrusion at the femoral head-neck junction. ${ }^{16}$ Our study shows one patient with CAM type of femoroacetabular impingement. A small bony protrusion is noted over the femur neck with intra substance tear of superior labrum. Alpha angle was around 64 degrees.

One limitation of our study is, we have diagnosed all the cases based on MRI evaluation, clinical and laboratory investigation, other modalities like arthroscopic evaluation/ nuclear study were not done and hence could not be compared with findings of those studies. As the study was done over a short period of time complete follow up of the patients could not be done.

\section{CONCLUSION}

MRI is a safe and non-invasive imaging modality for the diagnosis of various pathologies of hip joint. Due to its greater soft tissue contrast and resolution, MRI remains as modality of choice for the detection of joint pathologies, synovial changes, bone marrow abnormalities, articular cartilage pathologies and muscle abnormalities. Our study shows the importance of MRI in the evaluation of hip joint pathologies and thus guides the clinician with accurate diagnosis.

\section{REFERENCES}

1. Markisz JA, Knowles RJ, Altchek DW, Schneider RO, Whalen JP, Cahill PT. Segmental patterns of avascular necrosis of the femoral heads: early detection with MR imaging. Radiology. 1987;162(3):717-20.

2. Stoica Z, Dumitrescu D, Popescu M, Gheonea I, Gabor M, Bogdan N. Imaging of avascular necrosis of femoral head: familiar methods and newer trends. Current health sciences journal. 2009;35(1):23.

3. Verbeeten KM, Hermann KL, Hasselqvist M, Lausten GS, Joergensen P, Jensen CM, Thomsen HS. The advantages of MRI in the detection of occult hip fractures. European radiology. 2005;15(1):165-9.

4. Berquist TH, editor. MRI of the musculoskeletal system. Lippincott Williams \&Wilkins; 2012 Apr 6.

5. Riley GM, McWalter EJ, Stevens KJ, Safran MR, Lattanzi R, Gold GE. MRI of the hip for the evaluation of femoroacetabular impingement; past, present, and future. Journal of Magnetic Resonance Imaging. 2015;41(3):558-72.

6. Jacobs B. Epidemiology of traumatic and nontraumatic osteonecrosis. Clinical orthopaedics and related research. 1978(130):51-67.

7. Kamal D, TRĂISTARU R, Alexandru DO, Grecu DC, Mogoanta L. Epidemiologic Study of Avascular Necrosis of the Femoral Head. Current Health Sciences Journal. 2013;39(3).

8. Drar HA, Mohammed BA, Ali ZA. The role of MRI in the evaluation of painful hip joint (MRI of hip joint). International Journal of Medical Imaging. 2014;2(03):77-82.

9. Mitchell DG, Rao VM, Dalinka MK, Spritzer CE, Alavi A, Steinberg ME, Fallon M, Kressel HY. Femoral head avascular necrosis: correlation of MR imaging, radiographic staging, radionuclide imaging, and clinical findings. Radiology. 1987;162(3):709-15.

10. Deutsch AL, Mink JH, Waxman AD. Occult fractures of the proximal femur: MR imaging. Radiology. 1989;170(1):113-6.

11. Boutry N, Paul C, Leroy X, Fredoux D, Migaud H, Cotten A. Rapidly destructive osteoarthritis of the hip: MR imaging findings. American Journal of Roentgenology. 2002;179(3):657-63.

12. Silva F, Adams T, Feinstein J, Arroyo RA. Trochanteric bursitis: refuting the myth of inflammation. JCR: Journal of Clinical Rheumatology. 2008;14(2):82-6.

13. Karchevsky M, Schweitzer ME, Morrison WB, Parellada JA. MRI findings of septic arthritis and associated osteomyelitis in adults. American Journal of Roentgenology. 2004;182(1):119-22.

14. Saraf SK, Tuli SM. Tuberculosis of hip: A current concept review. Indian journal of orthopaedics. 2015;49(1):1.

15. Traill Z, Talbot D, Golding S, Gleeson FV. Magnetic resonance imaging versus radionuclide scintigraphy in screening for bone metastases. Clinical radiology. 1999;54(7):448-51.

16. Tannast M, Siebenrock KA, Anderson SE. Femoroacetabular impingement: radiographic diagnosis-what the radiologist should know. American Journal of Roentgenology. 2007;188(6):1540-52.

\section{Source of Support: Nil; Conflict of Interest: None}

Submitted: 24-08-2019; Accepted: 20-09-2019; Published online: 14-10-2019 